\title{
A measure of interpersonal dominance
}

\author{
PAUL D. KNOTT and BRUCE A. DROST, UNIVERSITY OF \\ DENVER, Denver, Colorado 80210
}

\begin{abstract}
Adolescent males, both delinquent and nondelinquent, were used in the development of a task in which two Ss first make separate decisions, then a joint decision regarding a number of paired photos of girls' faces. The task was developed in order to facilitate and encourage controlled experimentation in the study of interpersonal dominance.
\end{abstract}

One of many reasons for the present vigor and magnitude of research on dominance among animals is the availability of various reliable measures of actual dominance behavior. For example, Wilson (1968) and Hsiao and Schreiber (1968) report variations on the "dominance tube" technique whereby, in order to obtain a food reward, one rat must push an opposing rat through a tube too narrow for either $S$ to pass unhindered. Uyeno and White (1967) have adapted the dominance tube strategy to tests with rodents conducted under water. With human Ss, however, only tests of the paper-and-pencil variety are available at the present time, none of which has been shown to be highly reliable. Primarily because of the lack of direct behavioral measures of interpersonal dominance, the studies with humans have been in the main correlational, emphasizing factors such as leadership (Krech \& Crutchfield, 1948) and interpersonal choice (Altrocchi, 1959).

The purpose of the present research was to develop a behavioral measure of interpersonal dominance in order to facilitate and encourage controlled experimentation in the area. Dominance is defined, after Mann (1959), in terms of the number of contributions made by the individual members of a dyad toward a joint decision.

\section{METHOD}

Facial photographs of 200 coeds were taken from the yearbook of another university. The girls were rated for "prettiness" on a 7-point scale by 52 late adolescent males. Photographs that received the same rating were then randomly paired on $5 \times$ 8-in. white index cards. A new sample of 84 late adolescent males was then asked to state which one of the two girls was prettier on each card. Cards were removed and new ones inserted when it became clear that one girl was preferred consistently over the other. Eventually 30 comparisons were found in which there was no more than a $55 \%$ preference for either of the two girls on a card.

\section{STUDY 1}

The Ss were 20 Boy Scouts, 15 to 17 years old, who had spent eight consecutive summer weekends with each other, accompanied by two adult counselors. Each counselor was individually given written examples of "pecking orders" among animals and was subsequently asked if he could discern a pecking order among the 32 boys of the scout troop. Each of the counselors answered yes, thus each was asked to rate the 32 boys, starting with No. 1 (top of the pecking or dominance order) down to No. 32. The slight differences between the two ratings were not significant, thus, the ratings were pooled.

The top 10 boys were then paired randomly with the bottom 10. Each $S$ of the dyad faced the other over a 6 -ft long table. Identical sets of 30 cards were placed before each member of the dyad. The Ss were instructed to mark on a provided sheet their preferences, in terms of prettiness, for one of the two girls on each card. No talking was allowed; remarks directed at $E$, who sat across the room from the Ss, were ignored. When the initial, separate choices were completed, the Ss were told to go through the 30 cards again, in order, and "this time come to a group decision as to which girl is prettier on each card." The Ss were informed that they could now discuss the girls as much as they wished, and that they could keep and refer to their initial preference sheets. The dyad decisions were announced to and recorded by $\mathrm{E}$, who paid no attention to the dyad discussions and arguments.

\section{Results}

A "dominance score" of one point was recorded for a dyad member whenever his individual choice was the dyad's choice. Otherwise, no score was recorded. In all 10 dyads, the $S$ rated high in dominance (HD) had a higher sum dominance score than the $S$ rated low in dominance (LD). The sum dominance score for all of the HD Ss was 102 with a mean of 10.2. For LD Ss the sum dominance score was 23 with a mean of 2.3. A correlated t test indicated $\mathrm{t}=7.25, \mathrm{df}=9, \mathrm{p}<.001$.

\section{STUDY 2}

The Ss were 14 males, 15 to 17 years old, who were confined in a state reform school. 1 The procedure used in this study was identical to that of Study 1. In this study, the ratings were obtained from the two adult counselors who lived in the cottage with the boys. No differences in ratings were found. Originally, 11 dyads were obtained on the basis of the counselors' ratings, but only 7 were used; in 4 dyads one of the Ss either went AWOL or was placed in maximum security before he could be run.

\section{Results}

Scoring was the same as in Study 1. In six of seven dyads, the HD $S$ had a higher dominance score than the LDS. The sum dominance score for HD Ss was 68 with a mean of 9.71. For LD Ss, the sum dominance score was 23 with a mean of 3.29 . The correlated $\mathrm{t}$ test indicated $\mathrm{t}=2.52, \mathrm{df}=6, \mathrm{p}<.025$.

\section{DISCUSSION}

These results suggest that the present technique may be a viable way of studying interpersonal dominance. Currently, studies are being conducted to assess further the validity and reliability of the technique. If the test fulfills its promise it will have many positive features. It is quick and easy to administer, and it should make possible the study of the effects of reinforcement conditions, anxiety, aroused aggression, and various other variables on interpersonal dominance under conditions of controlled experimentation.

In both studies there were frequent and often heated arguments between dyad members. Some of the dominant Ss simply overwhelmed their opponents either by sheer verbal volume or, in a few cases, by implying or explicitly making physical threats to their opponents. Other dominant Ss engaged in a more subtle interplay whereby they appeared to be democratic with their opponents (e.g., all of the social niceties were observed), but in actual fact they were making nearly all of 
the decisions. The former techniques were more commonly observed in the second study whereas the latter strategies were more typically used in Study 1. Systematic attempts to categorize these behavioral interactions may prove to be fruitful in terms of generating hypotheses.

Adolescent males were used in this research since they would seem to be a prime group for study: They appear prone to "pecking orders" in gang activities and, in terms of crime statistics, they are the most aggressive age group in the population. The measure itself, however, was developed along lines suggested by Mann (1959), who reports that the number of task contributions by a member of a group correlates highly with other (pencil-and-paper) measures of dominance for that member. In line with Mann's reports, the strategy used in the present research might be workable with almost any group in the population. Children might be asked to decide among sets of paired toys. Females might be asked to decide between sets of paired pictures of attractive males or between sets of paired photos of attractive clothes.

One modification of the method would be to have a common stooge compete with the Ss. The stooge could be trained to respond in a standard, prescribed manner to each $S$ and his behavior rated by independent, unseen observers.

Another modification would be to use pairs of photos where both girls were, say, blond and blue-eyed, but one girl has been, in prior work, rated far prettier than the other. The numbers under the girls' photos would be reversed for the two members of the dyad, so that the picture of the homely girl would be Photo 1 for the LD S, but Photo 2 for the HD S. If, under these conditions, the HD S dominated the team's choices, one could feel confident about the dominance relationship between the two Ss.

\section{REFERENCES}

ALTROCCHI, J. Dominance as a factor in interpersonsl choice and perception. Journal of Abnormal \& Social Psycholozy, 1959, 59, 303-308.

HSIAO, S., \& SCHREIBER, S. C. Social dominance and motivational variables in rats. Psychonomic Science, 1968, 10, 117-118.

KRECH, D., \& CRUTCHFIELD, R. S. Theory and problems of social psychology. New York: McGraw-Hill, 1948.

MANN, R. D. A review of the relationships between personality and performance in small groups. Psychological Bulletin, 1959, 56, 241-270.

UYENO, E. T., \& WHITE, M. Social isolation and dominance behavior. Journal of Comparative \& Physiological Psy chology, 1967, 63, 157-159.

WLSON, W. J. Adaptation to the dominance tube. Psychonomic Science, $1968,10,119-120$.

\section{NOTE}

1. We wish to thank the officials and boys of the Lookout Mountain School for Boys of Golden, Colorado, for their cooperation in this research.

\section{A note on methods of indexing associative relatedness'}

PAUL E. JOHNSON ${ }^{2}$ and RAYMOND O. COLLIER, JR., UNIVERSITY OF MINNESOTA, Minneapolis, Minn. 55455

$A$ method of indexing response relations among stimulus words on a word association test is presented utilizing the concept of mathematical sets. Two coefficients of associative relatedness are proposed and some relationships between these and a number of other coefficients are given.

Methods for indexing relationships among the stimulus words on a word-association test have been presented by Deese (1962), Garskoff and Houston (1963), and Marshall and Cofer (1963). One group of methods defines the relatedness between two stimulus words as the ratio of the number of common responses to a basal measure that is a function of the total number of responses to the stimulus words. The specification of the number of common responses (the commonality) between two stimulus words is fairly well agreed upon by different investigators, except perhaps for the issue of representational or implicit responses (Deese, 1962, 1965). However, the basal measure between two stimulus words has been written in a number of ways. In the case of discrete association (each $S$ gives only one response to each stimulus word), Deese (1965) defines this basal quantity as the geometric mean of the total number of responses to the two stimulus words, while Marshall and Cofer (1963) define the basal measure as the sum of the number of responses for two stimulus words. For continued association (each S gives at least one response to each stimulus word) the total number of responses often varies among stimulus words and among Ss whereas the basal measure for two stimulus words for a given $\mathrm{S}$ can be written in terms of the number of responses in either the larger or the smaller of the two distributions. In the case of continued association, the commonality between two response distributions can also be formulated with a weighting factor so as to take account of the order in which responses are given (Garskoff \& Houston, 1963).

Coefficients of relatedness have been constructed, in the case of discrete association, for the purpose of indexing the response commonality among more than two stimulus words. Here, however, the counting rule used for determining commonality is different from the rule used for only two stimulus words, and also varies from coefficient to coefficient. Two such coefficients that have been proposed for two or more stimulus words are the index of total association (ITA) and the index of concept cohesiveness (ICC) (Marshall \& Cofer, 1963).

Methods of indexing associative relatedness can be conveniently classified according to whether they are based upon discrete or continued word association, and, jointly, according to whether they are formulated for two or for more than two stimulus words. None of the coefficients referred to previously were developed explicitly to deal with the situations in all categories in this 2 by 2 classification scheme. It is the purpose of this paper (a) to suggest a basis for defining a class of coefficients that is appropriate for discrete and continuous association and for two or more stimulus words, and (b) to develop explicitly coefficients for the case of discrete association and two or more stimulus words.

We consider the responses to a single stimulus word to be elements of a mathematical set. Responses to two or more 